\title{
Interactions among Heparin, Cold-Insoluble Globulin, and Fibrinogen in Formation of the Heparin-Precipitable Fraction of Plasma
}

\author{
Nicolas E. Stathakis and Michael W. Mosesson, Department of Medicine, \\ State University of New York Downstate Medical Center, Brooklyn, \\ New York 11203
}

A в S T R A C T Fibrinogen and the cold-insoluble globulin of plasma $(\mathrm{CIg})$ are the main protein components of the heparin-precipitable fraction of normal plasma. The interactions among these proteins and heparin were examined. Heparin formed a cold-precipitable complex with purified CIg or with mixtures of CIg and fibrinogen but not with purified fibrinogen alone. Cryoprecipitation was augmented by addition of $\mathrm{Ca}^{++}$ or by selection of optimal heparin levels; it was reduced or even abolished by raising the ionic strength or $\mathrm{pH}$ or both, or by raising the heparin concentration above that for maximum precipitation of CIg. Fibrinogen reduced the threshold for heparin-induced CIg cryoprecipitation and, by coprecipitating with heparin and CIg, increased the amount of precipitate that formed. In contrast to the heparin-precipitable fraction of normal plasma which contained both fibrinogen and CIg, that from a patient with congenital afibrinogenemia contained CIg but lacked fibrinogen. Normal plasma depleted of CIg by immunoabsorption failed to form a heparin-induced cryoprecipitate. Thus, CIg is essential for heparin-induced cryoprecipitation to occur. Fibrinogen, as assessed by chromatographic experiments with heparin-Sepharose columns, had a considerably lower binding affinity for heparin than did CIg, suggesting that it participates in precipitate formation mainly, if not entirely, by virtue of its affinity for CIg. The region of the fibrinogen molecule accounting for its precipitation with CIg appears to be localized in the carboxy-terminal segment of the $A \alpha$-chain; fibrinogen subfractions lack-

\footnotetext{
Results of this investigation were presented at the 6th Congress of the International Society on Thrombosis and Haemostasis, June 1977, Philadelphia, Pa.

Dr. Stathakis was a postdoctoral research fellow during the course of this research. His present address is Evangelismos Medical Center, Professional Unit, Athens, Greece.

Received for publication 31 March 1977 and in revised form 6 June 1977.
}

The Journal of Clinical Investigation Volume 60

ing this region failed to augment cryoprecipitation of heparin-CIg mixtures and, even though such species were present in normal plasma, they failed to coprecipitate in the heparin-induced complex.

\section{INTRODUCTION}

In 1954, Thomas et al. (1) reported the occurrence of heparin-induced cryoprecipitates in plasma from endotoxin-treated rabbits. This fraction has come to be known as the "heparin-precipitable fraction of plasma." Subsequent studies by Smith and von Korff (2) and Smith (3) showed that large amounts of cryoprecipitate were formed from plasmas of patients with certain inflammatory, infectious, and neoplastic diseases to which heparin had been added. This phenomenon was also observed when heparin was added to the plasma of normal donors, but the amount produced was usually less $(3,4)$. Smith and von Korff (2) found that cryoprecipitate formation was dependent upon heparin concentration and that it could be enhanced by the presence of divalent cations or reduced by increasing the temperature, ionic strength, or $\mathrm{pH}$. They established that fibrinogen was a major component of this fraction. This conclusion was based upon the observations that the heparin-precipitable fraction was partially coagulable with thrombin, that a portion of it was similar to fibrinogen in electrophoretic and ultracentrifugal behavior $\left(s_{20, w}, 7.9\right.$ to 8.3$)$, and that heparin-induced cryoprecipitation could not be produced in serum. They suggested that the fibrinogen in the precipitate might have been modified in some way because purified preparations of fibrinogen were only partially cryoprecipitable in the presence of heparin.

They also observed a second minor component of the fraction $\left(s_{20, w}, 12.5 \mathrm{~S}\right)$ which they thought might be a form of fibrinogen, and they drew attention to its similarity to a component of normal plasma subfraction I-1 termed "cold-insoluble globulin" (5). Sub- 
sequent investigations of a patient with ovarian carcinoma (6), and of plasma subfractions like fraction I-1, led to characterization of "cold-insoluble globulin", (CIg), ${ }^{1}$ as a normal plasma glycoprotein that is structurally and immunochemically distinct from fibrinogen and all other plasma proteins $(7,8)$. CIg normally circulates at plasma levels of $0.33 \pm 0.1$ $\mathrm{g} /$ liter (7); the level in serum is somewhat lower owing to incorporation of some of it into the fibrin clot $(7,9$, $10)$, to which it can be covalently bound by factor XIIIa $(10,11)$.

Smith and von Korff's original speculation (2) regarding the presence of CIg in the heparin-precipitable fraction has recently been supported. It has been shown, on the basis of electrophoretic and immunochemical analyses, that $\mathrm{CIg}$ is a major protein component of the heparin-induced plasma cryoprecipitate of patients with certain dermatological diseases (12). Similar studies of dermatologic patients (13), although not employing immunochemical identification of CIg, have also permitted the same conclusion. However, it is not yet clear what role CIg plays in formation of the precipitate or what the relationship is between heparin-induced cryoprecipitates and those that form spontaneously in the cold without requiring addition of heparin (the latter type are popularly termed "cryofibrinogen"). Many studies since the classic report of Shainoff and Page (14) have indicated that most spontaneously occurring plasma cryoprecipitates contain fibrin in a complex with fibrinogen and perhaps with other proteins as well (6). On the other hand, studies of the heparin-precipitable fraction from dermatologic patients (15) indicated that fibrinogen, but not fibrin, was a component of this type of cryoprecipitate.

To clarify some of the questions raised by studies cited above, we have undertaken a systematic investigation of the nature of plasma cryoprecipitates. The studies to be described in this report were designed to elucidate the mechanism of formation of the heparinprecipitable fraction of plasma. We have focused particularly upon the interactions taking place among the major components of this fraction: CIg, fibrinogen, and heparin.

\section{METHODS}

Preparation and analysis of fibrinogen and CIg. Fibrinogen subfractions I-2, I-4, I-8, and I-9 were prepared from outdated human acid citrate dextrose plasma as previously described $(16,17)$. Investigations of the amino terminal acids of these fractions $(17,18)$ have shown traces, at most, of glycine, an amino acid indicating the presence of fibrin in the preparation. The thrombin coagulability of each fraction was $>95 \%$. Purified human CIg was prepared by a modifica-

${ }^{1}$ Abbreviation used in this paper: CIg, cold-insoluble globulin. tion (19) of our original method (7). The concentrations of purified fibrinogen and CIg were determined spectrophotometrically at $\mathrm{pH} 7$ assuming absorption coefficients $\left(\mathbf{A}_{1}{ }_{\mathrm{cm}}\right)$ at $280 \mathrm{~nm}$ of $15.2(20)$ and $12.8(7)$, respectively.

$\mathrm{CIg}$ or fibrinogen concentration in plasma or related solutions was also determined by electroimmunoassay (21) on glass slides, $5 \times 7 \mathrm{~cm}$, coated with antibody-containing agarose in $\mathrm{pH} 8.6$ barbital buffer (I, 0.05). Electrophoresis was carried out for $16 \mathrm{~h}$ at $60 \mathrm{~V}$. The rabbit anti-human $\mathrm{CIg}$ serum was that previously reported (7). Studies confirming the specificity of this antiserum for CIg have previously been reported $(7,19,22,23)$. The rabbit anti-human fibrinogen serum had been prepared in this laboratory and was specific for fibrinogen (7).

The fibrinogen used in these studies was free of detectable fibrin as assessed by the following criteria: when subjected to chromatography (24) on Sepharose 4B (Pharmacia Fine Chemicals, Inc., Piscataway, N. J.), the fibrinogen emerged in a single symmetrical peak; the "ethanol gelation" test (25) was negative; no cryoprecipitate formed upon incubation at $2-4^{\circ} \mathrm{C}$. Occasional preparations giving evidence of small amounts of "fibrin" or aggregates by one or more of the above criteria were subjected to chromatography at room temperature on a $0.9 \times 25-\mathrm{cm}$ fibrinogen-Sepharose affinity column (26); in such a system fibrin selectively binds to the column. After this additional treatment, the material met all the criteria described above for fibrinfree fibrinogen, and behaved in the same way as fibrinogen preparations not requiring such treatment.

The CIg contaminant ( $3-4 \%$ by electroimmunoassay) in fibrinogen fraction I-2 was reduced by diethylaminoethylcellulose gradient elution chromatography $(7,18)$ carried out at room temperature. In this chromatographic system, fibrinogen is eluted in two main peaks, the first of which ("peak l") represents approximately $85 \%$ of the total fibrinogen in the fraction (27), and emerges considerably before the CIg peak (7). Material from this peak had a CIg content ranging from $<0.2$ to $1 \%$ and was used in experiments requiring CIgpoor fibrinogen.

Preparation of plasma samples. Fresh normal single donor human blood for studying heparin interactions was collected in $1 / 50 \mathrm{vol}$ of $19 \%$ sodium citrate in polystyrene tubes; some samples were collected into citrate solutions containing Kunitz' pancreatic trypsin inhibitor (Trasylol, FBA Pharmaceuticals, Inc., N. Y.; $500 \mathrm{U} / \mathrm{ml}$, final concentration) and hirudin (Pentapharm Ltd., Basel, Switzerland; $20 \mathrm{U} / \mathrm{ml}$, final concentration). Plasma was prepared from this blood by centrifugation at $2,000 \mathrm{~g}$ for $20 \mathrm{~min}$ at $4^{\circ} \mathrm{C}$, pooled with that of one or two other donors, and used immediately or stored at $-20^{\circ} \mathrm{C}$ for up to 2 days before use. Single donor units of fresh frozen acid citrate dextrose plasma were also used for experiments involving recovery of heparin from the heparin-precipitable fraction (see below). Citrated plasma from a patient with congenital afibrinogenemia was generously provided by Dr. Lyman Fisher(Medical College of Virginia, Richmond, Va.). The level of fibrinogen in this plasma was undetectable by electroimmunoassay (assay sensitivity 6-8 $\mu \mathrm{g} / \mathrm{ml}$ or less); its CIg level was $540 \mu \mathrm{g} / \mathrm{ml}$.

Normal plasma depleted of CIg was prepared in two ways. Fresh normal plasma (CIg level $310 \mu \mathrm{g} / \mathrm{ml}$ ) containing Trasylol and hirudin was depleted of $\mathrm{CIg}$ by addition of the IgG fraction $(0.1 \mathrm{ml} / \mathrm{ml}$ plasma) prepared from rabbit antihuman CIg serum; the immunoprecipitate that formed after several hours was removed at $4^{\circ} \mathrm{C}$ by centrifugation at $17,000 \mathrm{~g}$ for $30 \mathrm{~min}$. Such CIg-depleted plasma (CIg level $<10 \mu \mathrm{g} / \mathrm{ml}$ ) had a normal fibrinogen level $(2.2 \mathrm{mg} / \mathrm{ml})$. Alternatively, plasma was depleted of $\mathrm{CIg}$ by addition of unmodified rabbit anti-human CIg serum $(0.2 \mathrm{ml} / \mathrm{ml}$ plasma). 
CIg-depleted plasma prepared by either procedure behaved in a similar way in the experiments to be described.

Procedures involving heparin. Several preparations of heparin were used and included a liquid preparation for intravenous administration ( $\mathrm{Na}$ salt, Upjohn Co., Kalamazoo, Mich.; specific anti-coagulant activity 100 U.S. Pharmacopeia $\mathrm{U} / \mathrm{mg}$ ) and two heparin preparations in powdered form ( $\mathrm{Li}$ salt, grade IV, $158 \mathrm{U}$. S. Pharmacopeia U/mg, and Na salt, grade I, 158 U. S. Pharmacopeia U/mg, Sigma Chemical Co., St. Louis, Mo.). The heparin preparation used in any given experiment was the Upjohn product unless otherwise indicated.

The rate and extent of cryoprecipitation of plasma samples or mixtures of $\mathrm{CIg}$ and fibrinogen were monitored spectrophotometrically in 1-ml cuvettes as follows: CIg-fibrinogen mixtures (initial volume usually $<0.2 \mathrm{ml}$ ) were adjusted to a final volume of $1 \mathrm{ml}$ with $0.05 \mathrm{M}$ sodium phosphate- $0.1 \mathrm{M}$ $\mathrm{NaCl}$ buffer, pH 7.2 (I, 0.2); plasma samples were diluted $1: 2$ with this buffer. For experiments involving determination of the effect of $\mathrm{Ca}^{++}$, a $0.05 \mathrm{M}$ Tris- $\mathrm{HCl}, 0.1 \mathrm{M} \mathrm{NaCl}$, pH 7.2 buffer (I, 0.15) was used. The filled cuvettes were placed in a Gilford spectrophotometer (model 240; Gilford Instrument Laboratories Inc., Oberlin, Ohio). The temperature of the jacketed cuvette chamber was maintained at $2^{\circ} \mathrm{C}$, and the formation of precipitate (i.e., increase in light scattering) followed by absorbance measurements at $350 \mathrm{~nm}$. The readings obtained for heparin-containing mixtures were corrected by using as a blank a sample of the same mixture incubated under the same conditions without added heparin. Elevations in blank readings during the course of an experiment were small ( 0.030 or less). The heparininduced precipitate forming during the first $5 \mathrm{~h}$ in the absence of $\mathrm{Ca}^{++}$was too fine to appreciate the presence of any discrete particles; there was no tendency for the precipitates to settle out unless subjected to centrifugation. Maximal light scattering under most experimental conditions usually developed within $1 \mathrm{~h}$ and always within $3 \mathrm{~h}$ of incubation. Unless otherwise specified, we reported only the reading taken at $3 \mathrm{~h}$. The curves were very reproducible for any given set of conditions.

The heparin-precipitable fraction from fresh normal or afibrinogenemic plasma was obtained by incubating $1-10$ $\mathrm{ml}$ of plasma in the presence of heparin at $2-4^{\circ} \mathrm{C}$ for $16 \mathrm{~h}$. The precipitate that formed was harvested at $4^{\circ} \mathrm{C}$ by centrifugation at $10,000 \mathrm{~g}$ for $30 \mathrm{~min}$, extracted three times at $4^{\circ} \mathrm{C}$ with $0.15 \mathrm{M} \mathrm{NaCl}-0.05 \mathrm{M}$ Tris- $\mathrm{HCl}$ buffer, $\mathrm{pH} 7.2$ (I, 0.2), resuspended in the same buffer, and brought into complete solution by incubation for $20 \mathrm{~min}$ to $2 \mathrm{~h}$ at $37^{\circ} \mathrm{C}$. Without the addition of heparin, no such precipitate could be recovered from normal or afibrinogenemic plasma.

For the chromatographic experiments described below, the heparin-precipitable fraction from $140 \mathrm{ml}$ fresh frozen acid citrate dextrose plasma (prepared with the $\mathrm{Li}$ or $\mathrm{Na}$ heparin preparations at a final concentration of $0.10 \mathrm{mg} / \mathrm{ml}$ ) was extracted once with ice-cold $0.05 \mathrm{M}$ Tris-phosphate buffer, $\mathrm{pH}$ 7 (I, 0.1), and then dissolved at $37^{\circ} \mathrm{C}$ in $0.25 \mathrm{M}$ Trisphosphate buffer, $\mathrm{pH} 7$. To recover the heparin precipitated with this fraction, the dissolved fraction was diluted with water to a phosphate concentration of $\sim 0.05 \mathrm{M}$ and then applied to a diethylaminoethyl-cellulose (DE-23, Whatman, Inc., Clifton, N. J.) column $(0.9 \times 30 \mathrm{~cm})$ that had previously been equilibrated with $0.05 \mathrm{M}$ Tris-phosphate buffer, $\mathrm{pH} 7$. The column was flushed with additional $0.05 \mathrm{M}$ Trisphosphate buffer until the absorbance at $280 \mathrm{~nm}$ had returned to near the base line. Protein remaining adsorbed to the column was then eluted stepwise with Tris-phosphate buffers of increasing molarity to remove first the fibrinogen-enriched $(0.09 \mathrm{M})$ and then the CIg-enriched $(0.2 \mathrm{M})$ fractions, respectively $(7,19)$. After this, the column was flushed with $0.5 \mathrm{M} \mathrm{NaCl}$ to displace phosphate ions and remove any residual protein that remained. The heparin adsorbed to the column was then desorbed with $2 \mathrm{M} \mathrm{LiCl}$ (28). Heparin concentration was determined by a modification (28) of the Azure A method of Jaques et al. (29), with starting heparin as the standard. The anticoagulant activity of the heparin in the $\mathrm{LiCl}$ eluate peak was determined in platelet-poor citrated plasma by a thrombin time method (30); the activity, expressed in U. S. Pharmacopeia units, was based upon the reported anticoagulant activity of the starting heparin.

Heparin ( $\mathrm{Li}$ salt) was coupled to Sepharose $4 \mathrm{~B}$ as described by Miller-Anderson et al. (31). The amount of heparin that had been coupled was determined after hydrolysis of heparin-agarose gel samples (32) by the phenolsulfuric acid method (33) and was found to be $12 \mathrm{mg} / \mathrm{ml}$ gel. Stepwise elution chromatography on a heparin-Sepharose column $(0.9$ $\times 25 \mathrm{~cm}$ ) was carried out at room temperature or at $3 \pm 1^{\circ} \mathrm{C}$ at a flow rate of $16 \mathrm{ml} / \mathrm{h}$; fractions of $3.0 \pm 0.1 \mathrm{ml}$ were collected. The following buffers were used: buffer "A," 0.05 M Tris- $\mathrm{HCl}$ buffer, $\mathrm{pH} 7.2$ (I, 0.05); buffer "B," $0.10 \mathrm{M} \mathrm{NaCl}-$ $0.05 \mathrm{M}$ Tris- $\mathrm{HCl}$, pH 7.2 (I, 0.15); buffer "C," $0.4 \mathrm{M}$ $\mathrm{NaCl}-0.05 \mathrm{M}$ Tris- $\mathrm{HCl}$, pH 7.2 (I, 0.45); buffer “D," $1.0 \mathrm{M} \mathrm{NaCl}-0.05 \mathrm{M}$ Tris-HCl, pH 7.2 (I, 1.05). For certain experiments, the $\mathrm{pH}$ of buffer $\mathrm{A}$ was adjusted to 7.6 or 8.0. After each chromatographic experiment, the column was stripped with buffer $D$ and then reequilibrated with buffer $\mathrm{A}$. This affinity column was reused several times without apparent loss of binding activity.

Electrophoretic procedures. Dodecyl sulfate polyacrylamide gel electrophoresis was performed essentially as described by Weber and Osborn (34). The final gel polymerization mixture contained $0.05 \mathrm{M}$ sodium phosphate buffer, $\mathrm{pH} 7,4 \mathrm{M}$ urea, $0.1 \%$ sodium dodecyl sulfate and 3.5 or $5 \%$ acrylamide. For analyses of unreduced protein $(1-2$ $\mathrm{mg} / \mathrm{ml}$ ), samples were incubated for $2 \mathrm{~h}$ at $37^{\circ} \mathrm{C}$ in $8 \mathrm{M}$ urea, $1 \%$ sodium dodecyl sulfate, $0.005 \mathrm{M}$ sodium phosphate buffer, $\mathrm{pH}$ 7. For disulfide bond reduction, dithiothreitol (14 $\mathrm{mM}$, final concentration) was included. The samples were mixed with an equal volume of $50 \%$ ( $\mathrm{vol} / \mathrm{vol}$ ) glycerol, $0.01 \mathrm{M}$ sodium phosphate buffer, $\mathrm{pH} 7$, and then applied to the gels. Gels were stained with Coomassie Brilliant Blue as previously described (17). Densitometric scans of stained gels were carried out with a Gilford model 240 spectrophotometer equipped with a linear transport apparatus.

\section{RESULTS}

Cryoprecipitation of CIg and CIg-fibrinogen mixtures. Purified CIg $(\mathrm{pH} 7.2 ; \mathrm{I}, 0.2)$ at concentrations ranging from 15 to $500 \mu \mathrm{g} / \mathrm{ml}$ was incubated at $2^{\circ} \mathrm{C}$ with heparin $(0.05 \mathrm{mg} / \mathrm{ml})$. Incubation of $\mathrm{CIg}$ under the same conditions without heparin did not yield any detectable precipitate. In a typical experiment (Fig. 1), heparin-induced precipitation was first detectable at a CIg concentration of about $150 \mu \mathrm{g} / \mathrm{ml}$. At this level of heparin, the rate of precipitation and the amount of CIg precipiated became maximal at a CIg concentration of about $300 \mu \mathrm{g} / \mathrm{ml}$.

This same type of experiment was carried out in the presence of fibrinogen free of detectable CIg $(<0.2 \%)$. At fibrinogen concentrations ranging from $250 \mu \mathrm{g} / \mathrm{ml}$ to $6 \mathrm{mg} / \mathrm{ml}$, heparin-induced cryoprecipitation did not 


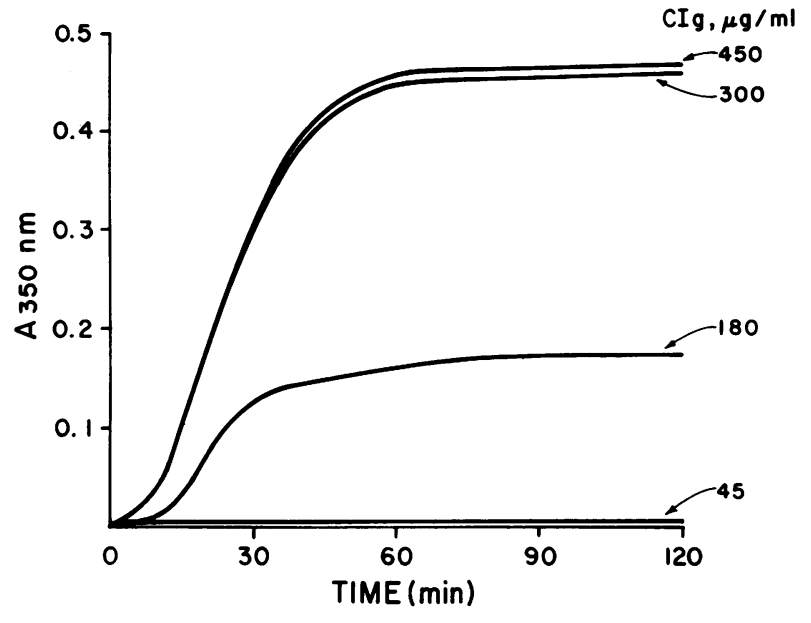

FIGURE 1 Heparin-induced cryoprecipitation $\left(2^{\circ} \mathrm{C}\right)$ of $\mathrm{CIg}$ (sodium phosphate buffer, $\mathrm{pH} 7.2 ; \mathrm{I}, 0.2$ ). Heparin was added to a final concentration of $0.05 \mathrm{mg} / \mathrm{ml}$. The formation of precipitate was monitored at $350 \mathrm{~nm}$. The concentration of CIg at which each precipitation curve was obtained is indicated.

take place until after CIg had been added (Fig. 2). The threshold CIg concentration for heparin-induced cryoprecipitation was markedly lower when fibrinogen was present and the amount of precipitate that formed was greater. This behavior was a clear indication that both CIg and fibrinogen had participated in the cryo-

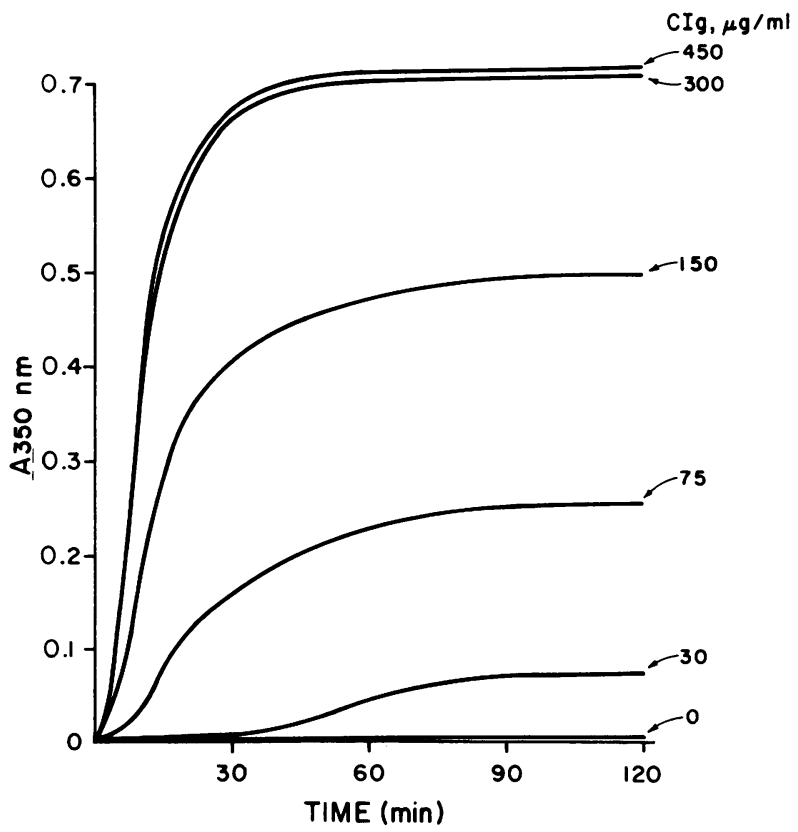

FIgURE 2 Heparin-induced cryoprecipitation of CIg and fibrinogen $(800 \mu \mathrm{g} / \mathrm{ml})$. Heparin concentration, temperature, and buffer conditions were those given in the legend to Fig. 1. The concentration of CIg at which each precipitation curve was obtained is indicated. precipitation phenomenon. However, the amount of precipitate forming at this heparin level $(0.05 \mathrm{mg} / \mathrm{ml})$ increased only up to a CIg concentration of 300 $\mu \mathrm{g} / \mathrm{ml}$, as had been the case in the previous experiment without fibrinogen (Fig. 1). This suggested that it was the amount of heparin, rather than fibrinogen, that determined the maximum amount of $\mathrm{CIg}$ in the cryoprecipitate. As was the case with heparin-CIg cryoprecipitates, the heparin-CIg-fibrinogen precipitate could be completely dissolved by incubation at $37^{\circ} \mathrm{C}$.

The effect of heparin concentration. The effect of heparin concentration on precipitation of purified CIg or CIg-fibrinogen mixtures was examined further (Fig. 3 ). Under any given set of buffer conditions favorable to precipitation, there was always an optimal range of heparin concentration at which maximum precipitation was achieved. When the heparin concentration was raised above the optimum level, the amount of precipitate progressively decreased. The shape of the precipitation curve of CIg-fibrinogen mixtures was the same as that of CIg alone, but the amount of precipitate at any given heparin concentration was greater in the presence of fibrinogen. In the experiment shown, the optimal heparin concentration range for precipitation of CIg was somewhat higher than it was for the CIg-fibrinogen mixture. Because the optimum level of heparin is dependent upon the CIg concentration (Figs. $1,2)$, this difference seems attributable to the fact that the $\mathrm{CIg}$ concentration in the CIg-fibrinogenheparin mixture was half that of the mixture of $\mathrm{CIg}$ and heparin.

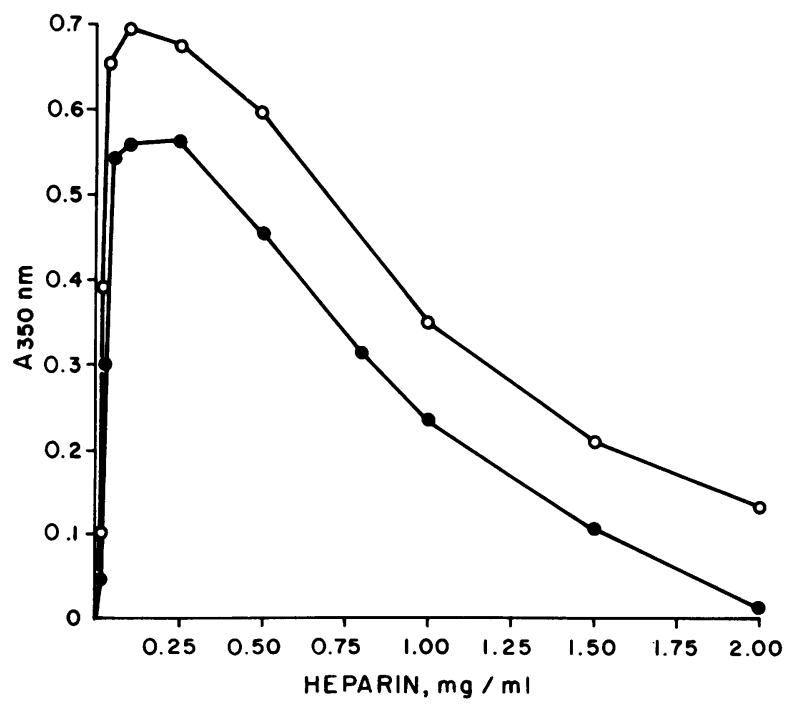

FIGURE 3 The effect of heparin concentration on cryoprecipitation of purified CIg $(300 \mu \mathrm{g} / \mathrm{ml})$, of CIg $(150 \mu \mathrm{g} / \mathrm{ml})$ and fibrinogen (fraction $\mathrm{I}-4,500 \mu \mathrm{g} / \mathrm{ml}$ ), $\mathrm{O}-\mathrm{O}$. Temperature and buffer conditions were those given in the legend to Fig. 1. 
The effect of ionic strength, $\mathrm{pH}$, and $\mathrm{CaCl}_{2}$. The effects of ionic strength and $\mathrm{pH}$ on $\mathrm{CIg}$ cryoprecipitation were examined (Fig. 4). The amount of heparininduced CIg cryoprecipitation decreased rapidly with increasing ionic strength or $\mathrm{pH}$ and was completely abolished at an ionic strength above 0.3 or at a $\mathrm{pH}$ above 9.0. At an ionic strength of 0.05 or lower at $\mathrm{pH} 7.0$ or less, $\mathrm{CIg}$ was precipitated at $2^{\circ} \mathrm{C}$ in the absence of heparin.

The effect of $\mathrm{CaCl}_{2}$ on cryoprecipitation was also assessed (Fig. 5). Its addition greatly increased the amount of precipitation that occurred in heparin-CIg or heparin-CIg-fibrinogen mixtures and resulted in more rapidly forming and more coarsely granular precipitates which, although ultimately soluble at $37^{\circ} \mathrm{C}$, did not redissolve as rapidly as did precipitates formed without added $\mathrm{CaCl}_{2}$. The addition of $\mathrm{CaCl}_{2}$ had no effect on CIg solutions lacking heparin or on fibrinogen-heparin mixtures lacking CIg. Consistent with this last observation, both heparin-CIg and heparin-CIg-fibrinogen mixtures showed a similar pattern of augmented precipitation in response to increasing $\mathrm{CaCl}_{2}$ concentration, suggesting that the $\mathrm{CaCl}_{2}$ effect is upon the heparin-CIg interaction.

The effect of fibrinogen catabolites. Human plasma fibrinogen fractions I-8 and I-9 (16) have been shown to consist of catabolic intermediate species, virtually all of which lack the carboxy-terminal portion of the

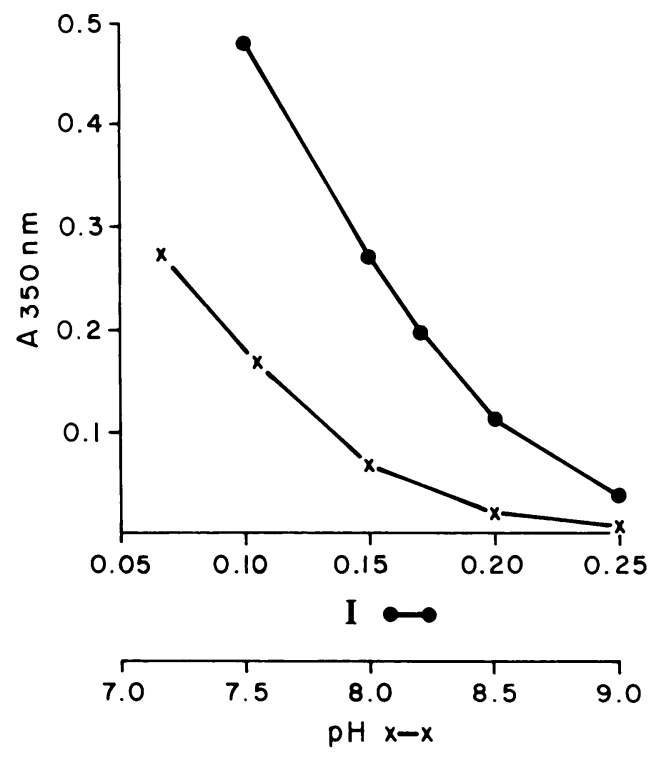

FIGURE 4 The influence of ionic strength and $\mathrm{pH}$ on heparininduced $(0.05 \mathrm{mg} / \mathrm{ml})$ cryoprecipitation $\left(2^{\circ} \mathrm{C}\right)$ of $\mathrm{CIg}(225$ $\mu \mathrm{g} / \mathrm{ml}$ ). In the experiments involving $\mathrm{pH}$ dependence, the ionic strength varied between 0.15 and $0.2(0.05 \mathrm{M}$ sodium phosphate, $0.05 \mathrm{M} \mathrm{NaCl}$ buffer). In experiments involving ionic strength dependence, $\mathrm{pH}$ was kept at $7.2(0.05 \mathrm{M}$ sodium phosphate buffer) while varying the concentration of $\mathrm{NaCl}$.

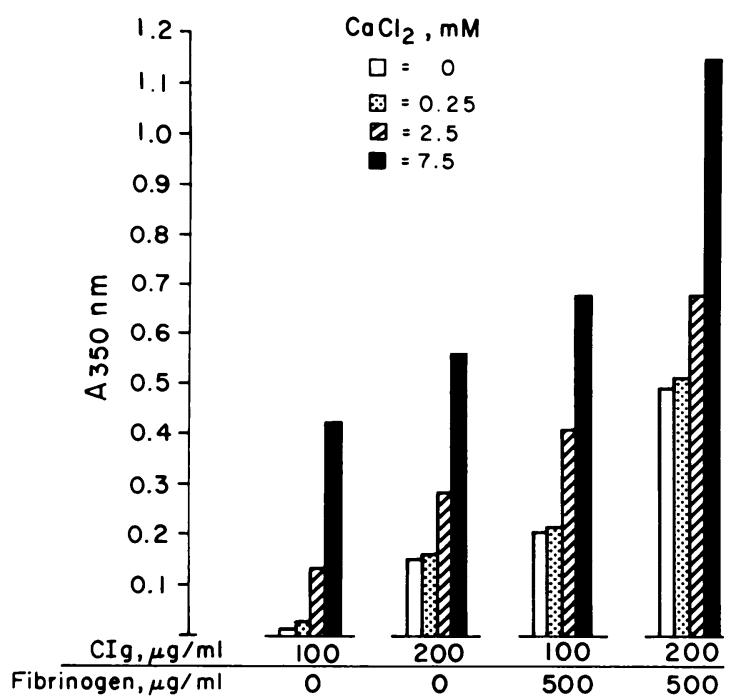

FIgure 5 The influence of $\mathrm{CaCl}_{2}$ on heparin-induced cryoprecipitation of $\mathrm{CIg}$ and $\mathrm{CIg}$-fibrinogen mixtures in Tris$\mathrm{HCl}, \mathrm{pH} 7.2$ buffer (I, 0.15). The $\mathrm{CaCl}_{2}$ concentration and the concentration of each protein component in the various mixtures are indicated. Heparin concentration and temperature were those given in the legend to Fig. 1.

A $\alpha$-chain (17). Fraction I-4, on the other hand, is comprised of less extensively catabolized fibrinogen species characterized by the presence of a very high proportion of intact $A \alpha$-chains. Heparin-induced cryoprecipitation of $\mathrm{CIg}$ in the presence of these subfractions was compared (Fig. 6). In contrast to the CIg-fraction I-4 mixture which, as expected, developed a much greater amount of precipitate than did CIg alone, the cryoprecipitate forming in the CIg-fraction I-8 and CIg-fraction I-9 mixtures differed only slightly from that of CIg alone.

Cryoprecipitation of normal, afibrinogenemic, and CIg-depleted plasma. Heparin-induced cryoprecipitation was carried out on normal plasma, that from an afibrinogenemic patient, or on normal plasma depleted of CIg (Fig. 7). CIg-depleted plasma exhibited only a slight increase in light scattering during the course of the experiment, whereas afibrinogenemic plasma developed a considerable amount of cryoprecipitate. Normal plasma yielded the greatest amount. As expected, the heparin-precipitable fraction harvested from fresh normal plasma was partially coagulable with thrombin, whereas that from afibrinogenemic plasma was not.

In related experiments, the optimal heparin level for CIg cryoprecipitation of normal or afibrinogenemic plasma was evaluted. Plasma was incubated with heparin at $2^{\circ} \mathrm{C}$ for $16 \mathrm{~h}$, the heparin-induced precipitate removed by centrifugation, and the $\mathrm{CIg}$ level in the supernatant plasma determined by immunoassay. The precipitation behavior of $\mathrm{CIg}$ in these plasmas

Heparin-Precipitable Fraction of Plasma 


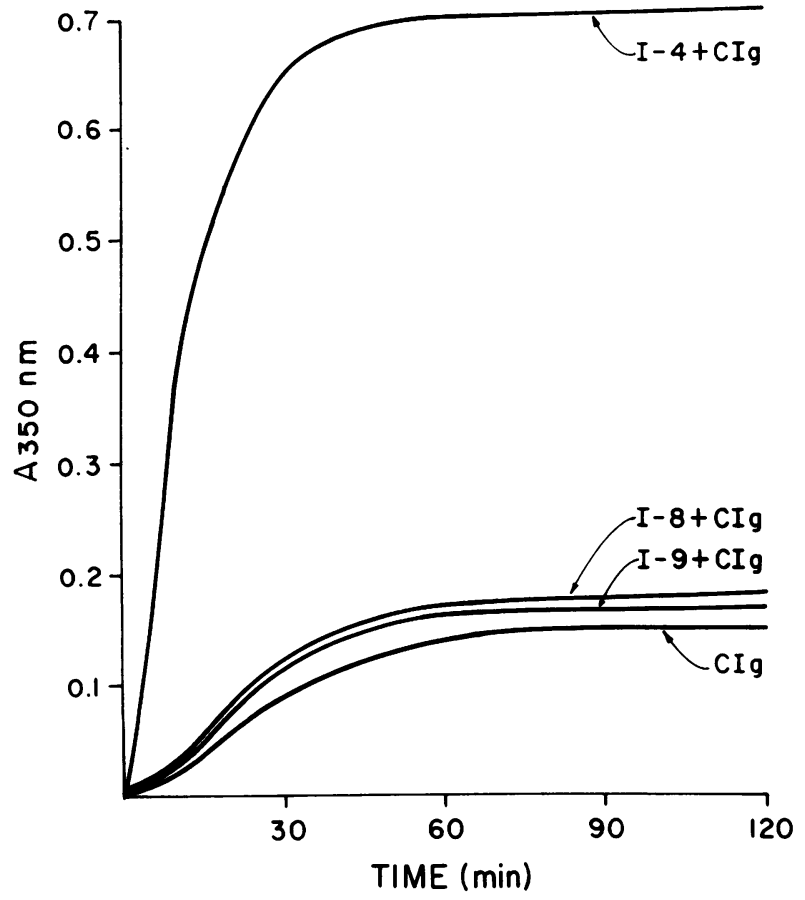

FIGURE 6 Heparin-induced cryoprecipitation of CIg (180 $\mu \mathrm{g} /$ $\mathrm{ml}$ ) in the absence or presence of fibrinogen fraction I-4 $(700 \mu \mathrm{g} / \mathrm{ml})$, I-8 $(790 \mu \mathrm{g} / \mathrm{ml})$, or I-9 $(660 \mu \mathrm{g} / \mathrm{ml})$. Heparin concentration, temperature, and buffer conditions were those given in the legend to Fig. 1.

was similar to that observed in mixtures of heparin with purified CIg or with CIg plus fibrinogen. That is, the amount of precipitate that formed at suboptimal heparin levels increased as a function of heparin concentration, whereas precipitation was progressively decreased at heparin levels exceeding those for maximum precipitation. The optimal heparin level for CIg precipitation in normal plasma (CIg level, $310 \mu \mathrm{g} / \mathrm{ml}$ ) was between 0.15 and $0.25 \mathrm{mg} / \mathrm{ml}$, and resulted in precipitation of $88 \%$ or more of the plasma CIg. This was also the optimal range observed for heparinCIg mixtures at a comparable CIg level (Fig. 3). Afibrinogenemic plasma required a somewhat higher heparin concentration $(\sim 0.50 \mathrm{mg} / \mathrm{ml})$ for maximum precipitation; probably reflecting the relatively higher level of CIg in this plasma $\left(540^{\circ} \mu \mathrm{g} / \mathrm{ml}\right)$.

Further characterization of normal or afibrinogenemic plasma was made by dodecyl sulfate gel electrophoretic analysis of the heparin-precipitable fraction (Fig. 8). The unreduced fraction from normal plasma revealed two main protein bands corresponding to those occupied by unreduced $\mathrm{CIg}^{2}$ and band I fibrino-

\footnotetext{
${ }^{2}$ Analytical ultracentrifugation and dodecyl sulfate gel electrophoretic analysis of CIg prepararations (8) have shown that most unreduced molecules exist as two-chain (mol wt $\sim 220,000$ /chain) disulfide-bridged units (mol wt $\sim 450,000$ );
}

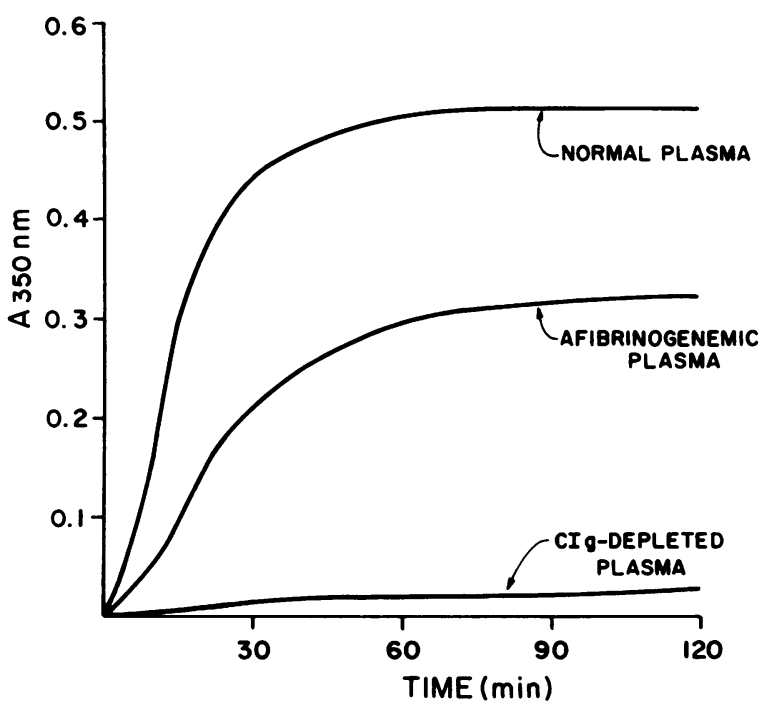

FIGURE 7 Heparin-induced cryoprecipitation of fresh normal plasma, afibrinogenemic plasma, and CIg-depleted plasma. The heparin concentration was $0.10 \mathrm{mg} / \mathrm{ml}$. Fresh normal plasma and afibrinogenemic plasma without added heparin yielded an absorbance curve that did not differ significantly from the one shown for CIg-depleted plasma plus heparin.

gen $^{3}$ (Fig. 8). In contrast, the afibrinogenemic heparin precipitate lacked the major fibrinogen band. In both samples, material with a slower migration rate than the CIg band of mol wt 450,000 probably represented noncovalent aggregates of CIg (23). Reduced samples of the heparin precipitate from normal plasma showed the characteristic band pattern of fibrinogen (i.e., bands corresponding to the $\mathrm{A} \alpha, \mathrm{B} \beta$, and $\gamma$ chains, respectively) and a major high molecular weight band corresponding to the position occupied by reduced $\mathrm{CIg}$ subunits (not shown). The reduced afibrinogenemic precipitate possessed only the major CIg band. Because of aggregation observed in unreduced normal plasma samples (Fig. 8), densitometric analyses were not attempted on such specimens. However, the relative proportion of $\mathrm{CIg}$ and fibrinogen in the precipitate from such plasma was assessed by densitometric scan-

lower molecular weight components bearing $\mathrm{CIg}$ antigenic determinants have also been described (23).

${ }^{3}$ Upon dodecyl sulfate electrophoresis, unreduced fractions I-4 or I-2 are resolved into two major bands, designated I and II (35). These bands differ with respect to their A $\alpha$-chain populations. Band I contains molecules with a very high proportion of intact $\mathbf{A} \alpha$-chains. In band II, a considerable proportion of the intact $A \alpha$-chains are replaced by a remnant chain termed $\mathbf{A} \alpha / 4$; this $\mathbf{A} \alpha$-remnant lacks a carboxy-terminal peptide having a mol wt of approximately 13,200 (calculated from the difference in size between $A \alpha, 70,900$, and $A \alpha / 4$, 57,700 ; [35]). Unreduced fractions I-8 and I-9 display bands with more rapid anodal migration rates than band II; this is due to the fact that the average size of the $A \alpha-$ remnant chains comprising these fractions is even smaller than those of molecules migrating in band II. 


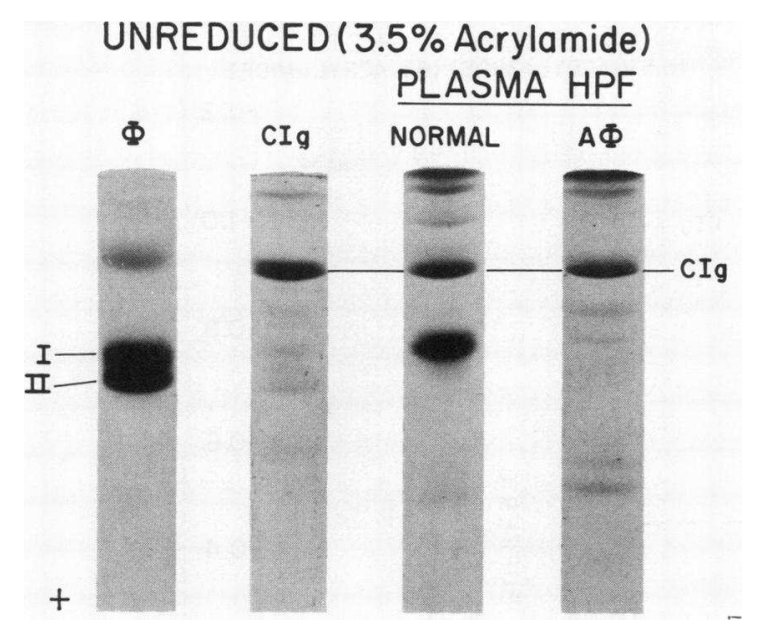

FIGURE 8 Dodecyl sulfate polyacrylamide gel electrophoresis of unreduced samples of fibrinogen fraction I-2 $(\phi)$ that is appreciably contaminated with CIg, purified CIg (CIg), and the heparin-precipitable fraction (HPF) from nor$\mathrm{mal}$ (Normal) or afibrinogenemic plasma (A $\phi)$. Electrophoresis was carried out for $3.5 \mathrm{~h}$ at $6 \mathrm{~mA} / \mathrm{gel}$. The two major fibrinogen bands (bands I and II) discernible in the fraction I-2 sample are indicated. The minor bands seen in addition to the main band in the CIg specimen reflect some of the multiple molecular forms of CIg.

ning of reduced gel samples; ${ }^{4}$ the results indicated that CIg accounted for about $35 \%$ of the stainable material, fibrinogen, $65 \%$.

Anticoagulant activity of heparin in the heparinprecipitable fraction. It is well known that heparin preparations consist of a group of closely related polydisperse glycosaminoglycans (36-39). Recent studies by Lam et al. (28) have shown that selective antithrombin-heparin cofactor binding activity is possessed by heparin molecules having a high specific anticoagulant potential. By utilizing this observation, they have been able to prepare heparin with specific anticoagulant activity of 348-388 U. S. Pharmacopeia U/mg from starting material with a sp act of only $155 \mathrm{U}$. S. Pharmacopeia U/mg. Others have reported similar findings $(40,41)$. To investigate whether heparin molecules possessing high anticoagulant activity have a special affinity for the protein components in the heparinprecipitable fraction, we determined the specific anticoagulant activity of heparin recovered by chromatography from the heparin precipitate of fresh-frozen normal plasma and that recovered by chromatography of starting heparin. The sp act of heparin recovered from the precipitate (accounting for $11-12 \%$ of the heparin added) was found to be $147 \mathrm{U}$. S. Pharmacopeia $\mathrm{U} / \mathrm{mg}$, a value slightly less than that of the starting material (158 U. S. Pharmacopeia U/ml) but virtually

4 This type of analysis, uncorrected for color yield or band spreading, probably results in underestimation of the proportion of CIg in the fraction. the same as heparin that had been subjected directly to the same chromatographic recovery procedures (151 U. S. Pharmacopeia U/mg).

Adsorption of CIg to a heparin affinity column. To better delineate the temperature-dependent nature of heparin-CIg complex formation and to investigate other variables, such as ionic strength and $\mathrm{pH}$, that influence its formation, we studied the adsorption behavior of $\mathrm{CIg}$ on a heparin-Sepharose column at $4^{\circ} \mathrm{C}$ and at room temperature. Under the buffer and temperature conditions we used, there was no significant binding of $\mathrm{CIg}$ or fibrinogen to Sepharose alone. However, with a heparin-Sepharose column, approximately $87 \%$ of the CIg (1.2 mg) applied in buffer A was adsorbed at $4^{\circ} \mathrm{C}$. No additional $\mathrm{CIg}$ was eluted when the temperature of the system was allowed to rise to room temperature but an additional $41 \%$ was desorbed with buffer B at room temperature. The remainder was subsequently eluted by buffer C. Desorption could also be brought about at room temperature or even at $4^{\circ} \mathrm{C}$ by using buffers of higher $\mathrm{pH}$. In a related experiment, CIgpoor fibrinogen prepared from fraction I-2 was applied to the column under the same conditions $(1.5 \mathrm{mg}$ protein; buffer $\mathrm{A} ; 4^{\circ} \mathrm{C}$ ); only $7 \%$ was retained.

Binding experiments were also carried out with normal plasma applied to the heparin-Sepharose column in buffer A (Fig. 9). Under the experimental conditions illustrated, $13 \%$ of the absorbance of the plasma, including $54 \%$ of the CIg and $2-4 \%$ of the fibrinogen, was retained by the column. The fibrinogen and CIg were subsequently recovered in the buffer C eluate peak. Dodecyl sulfate gel electrophoresis of material from this peak revealed numerous bands. One of these, a relatively weak staining band, had an anodal migration rate corresponding to that of $\mathrm{CIg}$ in reduced or unreduced samples. No further attempt was made in these experiments to characterize other bands in this fraction.

\section{DISCUSSION -}

Several previous studies, including that on a patient with ovarian carcinoma (6), have suggested that the main nonclottable component of the heparin-precipitable fraction, first clearly described by Smith and von Korff (2), would prove to be CIg. Indeed, Fyrand and Solum (12) and Matsuda et al. (13) have recently provided evidence that this is the case; our present studies confirm their conclusion. Fyrand and Solum did not specifically direct their attention toward defining the nature of the interactions of the main components of this fraction, but based upon the reported affinity of fibrinogen or fibrin for heparin $(42,43)$, they suggested that it is the interaction between fibrinogen and heparin that is crucial for formation of the fraction (12), and that CIg is included 


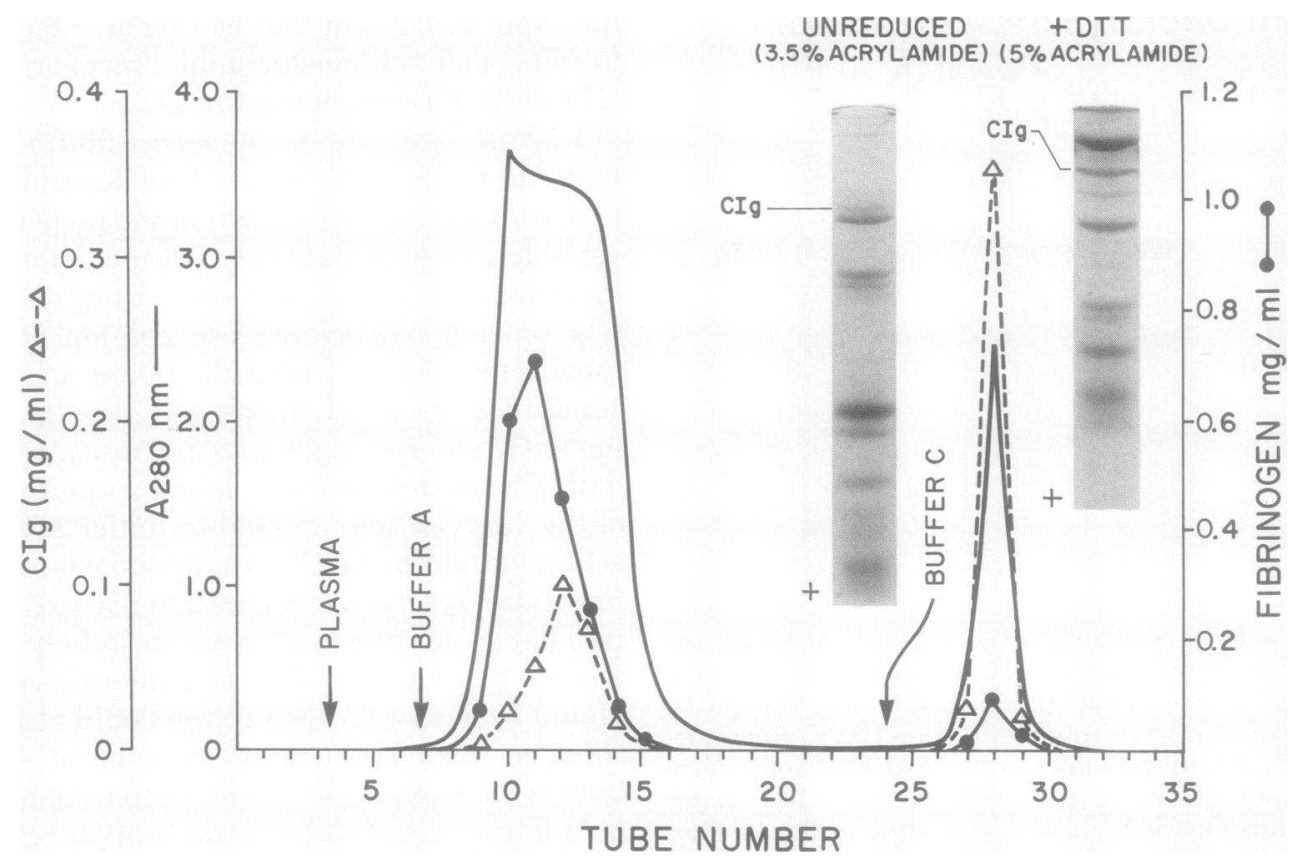

Figure 9 Characteristics of normal plasma applied to a heparin-Sepharose column. The 3$\mathrm{ml}$ plasma sample (fibrinogen concentration $2.4 \mathrm{mg} / \mathrm{ml}$, CIg concentration $280 \mu \mathrm{g} / \mathrm{ml}$ ) was diluted to $10 \mathrm{ml}$ with buffer $\mathrm{A}$ and applied to the column at room temperature. The column was then flushed with buffer A until absorbance readings had returned to base line. Buffer $\mathrm{C}$ was then applied. The fibrinogen or CIg concentration of each tube was determined by electroimmunoassay. Dodecyl sulfate gels of the unreduced (left) and reduced (right) material eluting with buffer $\mathrm{C}$ are shown. The band corresponding to the main CIg component of plasma ${ }^{2}$ is indicated.

in this precipitate only by virtue of its affinity for fibrinogen. Their finding that $\mathrm{CIg}$ levels were not always elevated in patients manifesting increased amounts of heparin precipitate (44) also implied a secondary role for $\mathrm{CIg}$ in its formation. Nevertheless, our present investigations provide compelling evidence for a different sequence of interactions among the components of the heparin-precipitable fraction. Most importantly, they indicate that CIg, not fibrinogen, plays the central role in mediating the formation of a heparin-induced plasma cryoprecipitate as represented by the following formula:

$$
\begin{array}{r}
\text { heparin + CIg } \underset{\downarrow}{\stackrel{22^{\circ} \mathrm{C}}{\longleftrightarrow} \text { heparin }} \cdot \stackrel{\text { CIg complexes }}{\uparrow} \underbrace{\uparrow} 2^{\circ} \mathrm{C} \\
\text { heparin } \cdot \mathrm{CIg} \text { precipitate. }
\end{array}
$$

The stoichiometry of such a reaction remains to be fully evaluated but we can calculate from our present data (such as in Fig. 3) that heparin molecules are present at $\sim 30$-fold molar excess or more relative to CIg (assumed mol wt of heparin, 11,000, [45]; CIg, 450,000, [8]) when optimal conditions for cryoprecipitation are reached. However, in our experiments related to determination of the anti-coagulant activity of heparin in the heparin-induced cryoprecipitate, only $11-12 \%$ of the amount added was recovered in the precipitate. Furthermore, preliminary results ${ }^{5}$ of heparin-induced cryoprecipitation of plasma using a tritiated heparin preparation (117 U. S. Pharmacopeia $\mathrm{U} / \mathrm{mg}$, generously provided by Dr. Grant Barlow, Abbott Laboratories, N. Chicago, Ill.) indicate that at optimal heparin concentrations, only $5-8 \%$ of added radioactivity is precipitated. These findings therefore suggest that the heparin:CIg ratio in the cryoprecipitate itself is in the range of 1.5-2.

Fibrinogen is neither essential for heparin-induced cryoprecipitation to occur nor does fibrinogen by itself form a cold-precipitable complex with heparin under the conditions we used. It is incorporated in the heparin-induced cryoprecipitate, and augments the process mainly, if not entirely, by virtue of its affinity for CIg. Furthermore, consistent with the findings of Smith and von Korff (2), the presence of divalent cations like $\mathrm{Ca}^{++}$was found to augment the rate and

\footnotetext{
${ }^{5}$ Stathakis, N. E., and M. W. Mosesson. Unpublished observations.
} 
amount of cryoprecipitate formation in mixtures of heparin with CIg or with CIg plus fibrinogen. The apparent lack of effect of $\mathrm{Ca}^{++}$upon heparin-fibrinogen mixtures thus emphasizes in another way the central importance of the CIg-heparin complex.

Our binding experiments with heparin-Sepharose columns indicate that complex formation between $\mathrm{CIg}$ and heparin is more dependent upon $\mathrm{pH}$ and ionic strength than it is upon temperature. In addition, like Gentry and Alexander (46), we found that heparin affinity for fibrinogen is weak. On the other hand, heparin-fibrinogen complexes can be formed under appropriate circumstances $(42,43,47-51$, inter alia), related for the most part to ionic strength and $\mathrm{pH}$ conditions, as is typical of electrostatic interactions between polyelectrolytes like heparin and proteins (52, 53). However, fibrinogen preparations are usually heavily contaminated with $\mathrm{CIg}(9,11$, and this study), and this fact has not been taken into account in certain experiments cited above whose proper interpretation would require differentiating effects due to indirect heparin binding of fibrinogen via CIg, from those due to direct binding. In any case, heparinfibrinogen complexes are probably not stable under ionic strength and $\mathrm{pH}$ conditions in the physiologic range (47).

Heparin is known to be capable of binding several plasma proteins $(51,54,55)$, including thrombin $(46$, $51,56,57)$ and certain other coagulation factors (46, 48 ), and an inhibitor known as antithrombin-heparin cofactor $(46,48,57,58)$. The results of our electrophoretic analyses of material from plasma that had been retained on a heparin-Sepharose column are consistent with those observations, in that several electrophoretic bands were found, including the minor one corresponding to $\mathrm{CIg}$ (Fig. 9). The numerous proteins binding to the heparin affinity column serve to underscore one of the unique features of the heparinCIg interaction, namely, that of all the heparinprotein complexes formed in plasma, only that between CIg and heparin appears to be cold-insoluble to any appreciable extent. That is, the relatively intense staining of the CIg band in the heparin-induced cryoprecipitate of normal or afibrinogenemic plasma is quite impressive when compared with its relatively weak intensity in the eluate fraction of the heparin affinity column (cf. Figs. 8 and 9). This fact, plus the discovery that plasma CIg can be precipitated in high yield in the presence of optimal amounts of heparin, offers a promising new first step in the purification of $\mathrm{CIg}$ which should result in a much higher recovery of material than can be obtained by application of presently existing preparative methods $(7,11,19)$. Furthermore, although a relatively simple ammonium sulfate precipitation method has been described (59) that can be used to prepare band I fibrinogen essentially free of fibrinogen catabolites, the use of heparin for this purpose introduces a new and simple way to obtain such molecules directly from plasma.

The antithrombin-heparin cofactor has an affinity for those heparin molecules possessing high anticoagulant activity $(28,40,41)$. This discovery provides a convenient means for separating heparin molecules with low anticoagulant potential from those with high potential. In our analysis of the heparin in the heparin-precipitable fraction, we observed that the specific anticoagulant activity of heparin recovered in this fraction was almost the same as that of the starting heparin. Failure to recover heparin of substantially higher or lower specific activity under precipitation conditions in which heparin was in molar excess with respect to CIg (heparin/CIg ratio $\approx 13-14: 1$ ) indicates that, unlike the plasma antithrombin-heparin cofactor, the heparin binding components of the heparin-induced precipitate are not selective for heparin molecules possessing high or low anticoagulant potential. This result is not surprising inasmuch as Smith and von Korff (2) were able to induce cryoprecipitation with a number of different sulfated polysaccharides that had little or no anticoagulant potential. Furthermore, they observed optimal precipitation in plasma at a heparin level in the same concentration range as we found in this study, although the specific anticoagulant activity of their preparation was not more than $1 / 10$ that of the preparations we used.

It is widely appreciated that fibrinogen is a major and constant constituent of the heparin precipitate of normal as well as of pathological plasma (2, 3, 13, 15). Certain early observations led to the inference that the fibrinogen in the fraction might have been altered in some way (2), perhaps by having been converted to a form of fibrin. Inasmuch as fibrin can circulate in a soluble form in blood under pathological conditions (14), and perhaps, to a limited extent, even in normal subjects (60), it might be included as a significant component of the heparin-precipitable fraction under proper circumstances. Nevertheless, our present studies support those of Fyrand et al. (15) in indicating that fibrin is not a usual or necessary component of the fraction from normal plasma. In fact, the fibrinogen in the heparin precipitate appears to be as close to the "native" form of the molecule as can be found in blood. That is, electrophoretic analyses indicate that fibrinogen in this fraction is characterized by the presence of intact $A \alpha$ chains (i.e., band I). ${ }^{3}$ Partially degraded circulating catabolites lacking portions of the molecule containing the carboxy-terminal portion of the $A \alpha$ chain, even though present in plasma $(35,59,61)$ or in mixtures of $\mathrm{CIg}$ and heparin, failed to participate in formation of such cold-precipitable complexes (Figs. 6 and 8). The failure of fibrinogen catabolites migrating in electrophoretic band II or 
beyond to participate in heparin-induced precipitation implies that the region of the fibrinogen $A \alpha$ chain accounting for precipitation with $\mathrm{CIg}$ is contained within a segment representing the difference in size $(\sim 13,200)$ between the intact $A \alpha$ chain and the principal A $\alpha$ chain remnant characterizing band II fibrinogen. ${ }^{6}$ The carboxy-terminal region of the $A \alpha$ chain also contains a site(s) that is utilized during factor XIIIacatalyzed cross-linking of fibrin $\alpha$ chains (62-64), and possibly during cross-linking with $\mathrm{CIg}(11)$ as well.

\section{ACKNOWLEDGMENTS}

We are most grateful to the medical illustrations/photography section for their help in preparing illustrative material, to Doctors Anthony B. Chen and Dennis K. Galanakis for many stimulating discussions, to Mr. Peter D. Natale for expert technical assistance, and to Mrs. Lori Hubert for outstanding secretarial assistance. We also thank Dr. John S. Finlayson for his penetrating criticisms of the manuscript.

This work was supported by a Program Project Research grant (HL-17419) from the National Heart and Lung Institute.

\section{REFERENCES}

1. Thomas, L., R. T. Smith, and R. W. von Korff. 1954. Cold precipitation by heparin of a protein in rabbit and human plasma. Proc. Soc. Exp. Biol. Med. 86: 813-819.

2. Smith, R. T., and R. W. von Korff. 1957. A heparinprecipitable fraction of human plasma. I. Isolation and characterization of the fraction. J. Clin. Invest. 36: 596604.

3. Smith, R. T. 1957. A heparin-precipitable fraction of human plasma. II. Occurrence and significance of the fraction in normal individuals and in various disease states. J. Clin. Invest. 36: 605-616.

4. Heinrich, R. A., E. C. Vonder Heide, and A. R. W. Climie. 1963. Cryofibrinogen: formation and inhibition in heparinized plasma. Am. J. Physiol. 204: 419-422.

5. Morrison, P. R., J. T. Edsall, and S. G. Miller. 1948. Preparation and properties of serum and plasma proteins. XVIII. The separation of purified fibrinogen from fraction I of human plasma. J. Am. Chem. Soc. 70: 3103-3109.

6. Mosesson, M. W., R. W. Colman, and S. Sherry. 1968. Chronic intravascular coagulation syndrome: report of a case with special studies of an associated plasma cryoprecipitate ("cryofibrinogen"), N. Engl. J. Med. 278: 815-821.

7. Mosesson, M. W., and R. A. Umfleet. 1970. The coldinsoluble globulin of human plasma. I. Purification, primary characterization, and relationship to fibrinogen and other cold-insoluble fraction components. J. Biol. Chem. 245: 5728-5736.

8. Mosesson, M. W., A. B. Chen, and R. M. Huseby. 1975. The cold-insoluble globulin of human plasma: studies of its -essential-structural features. Biochim. Biophys. Acta. 386: 509-524.

${ }^{6}$ The results do not permit us to distinguish whether two such sites per molecule (or just one) are required for precipitate formation, whether the CIg-binding site is actually contained within this segment or, less likely, whether the site(s) is situated elsewhere in the molecule but is masked by conformational rearrangements resulting from the loss of that segment.
9. Ruoslahti, E., and A. Vaheri. 1975. Interaction of soluble fibroblast surface antigen with fibrinogen and fibrin: identity with cold insoluble globulin of human plasma. J. Exp. Med. 141: 497-501.

10. Mosher, D. F. 1976. Action of fibrin-stabilizing factor on cold-insoluble globulin and $\alpha_{2}$-macroglobulin in clotting plasma. J. Biol. Chem. 251: 1639-1645.

11. Mosher, D. F. 1975. Cross-linking of cold-insoluble globulin by fibrin-stabilizing factor. J. Biol. Chem. 250: 6614-6621.

12. Fyrand, O., and N. O. Solum. 1976. Heparin precipitable fraction (HPF) from dermatological patients. II. Studies on the non-clottable proteins: identification of cold insoluble globulin as the main non-clottable component. Thromb. Res. 8: 659-672.

13. Matsuda, M., T. Saida, and R. Hasegawa. 1976. Cryofibrinogen in the plasma of patients with skin ulcerative lesions on the legs: a complex of fibrinogen and cold insoluble globulin. Thromb. Res. 9: 541-552.

14. Shainoff, J. R., and I. H. Page. 1960. Cofibrins and fibrinintermediates as indicators of thrombin activity in vivo. Circ. Res. 8: 1013-1021.

15. Fyrand, O., N. O. Solum, and P. Kierulf. 1976. Heparin precipitable fraction (HPF) from dermatological patients. I. Characterization of the thrombin-clottable protein. Thromb. Res. 8: 17-29.

16. Mosesson, M. W., and S. Sherry. 1966. The preparation and properties of human fibrinogen of relatively high solubility. Biochemistry. 5: 2829-2835.

17. Mosesson, M. W., J. S. Finlayson, R. A. Umfleet, and D. Galanakis. 1972. Human fibrinogen heterogeneities. I. Structural and related studies of plasma fibrinogens which are high solubility catabolic intermediates. J. Biol. Chem. 247: 5210-5219.

18. Mosesson, M. W., N. Alkjaersig, B. Sweet, and S. Sherry. 1967. Human fibrinogen of relatively high solubility: comparative biophysical, biochemical, and biological studies with fibrinogen of lower solubility. Biochemistry. 6: 3279-3287.

19. Chen, A. B., and M. W. Mosesson. 1977. An improved method for purification of the cold-insoluble globulin of human plasma (CIg). Anal. Biochem. 79: 144-151.

20. Mosesson, M. W., and J. S. Finlayson. 1963. Subfractions of human fibrinogen: preparation and analysis. J. Lab. Clin. Med. 62: 663-674.

21. Laurell, C-B. 1972. Electroimmunoassay. Scand. J. Clin. Lab. Invest. 29 (Suppl. 124): 21-37.

22. Cooper, H. A., R. H. Wagner, and M. W. Mosesson. 1974. The cold-insoluble globulin of plasma and its relationship to factor VIII. J. Lab. Clin. Med. 84: 258-263.

23. Chen, A. B., D. L. Amrani, and M. W. Mosesson. 1977. Heterogeneity of the cold-insoluble globulin of plasma, a circulating cell surface protein. Biochim. Biophys. Acta. 493: 310-322.

24. Fletcher, A. P., N. Alkjaersig, J. O'Brien, and V. Tulevski. 1970. Blood hypercoagulability and thrombosis. Trans. Assoc. Am. Physicians. 83: 159-167.

25. Godal, H. C., and U. Abildgaard. 1966. Gelation of soluble fibrin in plasma by ethanol. Scand. J. Haematol. 3: $342-350$.

26. Heene, D. L., and F. R. Matthias. 1973. Adsorption of fibrinogen derivatives on insolubilized fibrinogen and fibrinmonomer. Thromb. Res. 2: 137-154.

27. Finlayson, J. S., and M. W. Mosesson. 1963. Heterogeneity of human fibrinogen. Biochemistry. 2: 42-46.

28. Lam, L. H., J. E. Silbert, and R. D. Rosenberg. 1976. The separation of active and inactive forms of heparin. Biochem. Biophys. Res. Commun. 69: 570-577. 
29. Jacques, L. B., F. C. Monkhouse, and M. J. Stuart. 1949. A method for the determination of heparin in blood. J. Physiol. (Lond.). 109: 41-48.

30. Godal, H. C. 1974. Heparin assay methods for control of in vivo heparin effects. Thromb. Diath. Haemorrh. 33: 77-80.

31. Miller-Anderson, M., H. Borg, and L-O. Andersson. 1974. Purification of antithrombin III by affinity chromatography. Thromb. Res. 5: 439-452.

32. Moore, S. 1968. Amino acid analysis: aqueous dimethyl sulfoxide as solvent for the ninhydrin reaction. J. Biol. Chem. 243: 6281-6292.

33. Dubois, M., K. A. Gilles, J. K. Hamilton, P. A. Rebers, and F. Smith. 1956. Colorimetric method for determination of sugars and related substances. Anal. Chem. 28: 350-356.

34. Weber, K., and M. Osborn. 1975. Proteins and sodium dodecyl sulfate: molecular weight determination on polyacrylamide gels and related procedures. In The Proteins. H. Neurath and R. H. Hill, editors. Academic Press, Inc., New York. 1: 179-223.

35. Mosesson, M. W., D. K. Galanakis, and J. S. Finlayson. 1974. Comparison of human plasma fibrinogen subfractions and early plasma fibrinogen derivatives. J. Biol. Chem. 249: 4656-4664.

36. Laurent, T. C. 1961. Studies of fractionated heparin. Arch. Biochem. Biophys. 92: 224-231.

37. Walton, P. L., C. R. Ricketts, and D. R. Bangham. 1966. Heterogeneity of heparin. Br. J. Haematol. 12: 310-325.

38. Ehrlich, J., and S. S. Stivala. 1973. Chemistry and pharmacology of heparin. J. Pharm. Sci. U. A. R. 62: 517544.

39. McDuffie, N. M., C. P. Dietrich, and H. B. Nader. 1975. Electrofocusing of heparin: fractionation of heparin into 21 components distinguishable from other acidic mucopolysaccharides. Biopolymers. 14: 1473-1486.

40. Höök, M., I. Björk, J. Hopwood, and U. Lindahl. 1976. Anticoagulant activity of heparin: separation of high activity and low activity heparin species by affinity chromatography on immobilized antithrombin. FEBS (Fed. Eur. Biochem. Soc.). Lett. 66: 90-93.

41. Andersson, L-O., T. W. Barrowcliffe, E. Holmer, E. A. Johnson, and G. E. C. Sims. 1976. Anticoagulant properties of heparin fractionated by affinity chromatography on matrix-bound antithrombin III and by gel filtration. Thromb. Res. 9: 575-583.

42. Godal, H. C. 1960. Precipitation of human fibrinogen with heparin. Scand. J. Clin. Lab. Invest. 12: 56-65.

43. Godal, H. C. 1961. Binding of heparin to fibrin(ogen). Scand. J. Clin. Lab. Invest. 13: 550-552.

44. Fyrand, O., and N. O. Solum. 1976. Studies on cold insoluble globulin in dermatological patients. I. Immunochemical quantitation in citrated plasma from patients with increased amounts of heparin precipitable fraction (HPF). Thromb. Res. 9: 447-455.

45. Hilborn, J. C., and P. A. Anastassiadis. 1971. Estimation of the molecular weight of acidic mucopolysaccharides by polyacrylamide gel electrophoresis. Anal. Biochem. 39: 88-92.

46. Gentry, P. W., and B. Alexander. 1973. Specific coagu- lation factor adsorption to insoluble heparin. Biochem. Biophys. Res. Commun. 50: 500-509.

47. Bernfeld, P. 1966. Interaction of polyanions with blood components. In The Amino Sugars. E. A. Balazs and R. W. Jeanloz, editors. Academic Press, Inc., New York. 2B: 252-265.

48. Porter, P., M. C. Porter, and J. N. Shanberge. 1967. Interaction of heparin with the plasma proteins in relation to its antithrombin activity. Biochemistry. 6: 18541863.

49. Abildgaard, U. 1968. Inhibition of the thrombin-fibrinogen reaction by heparin in the absence of cofactor. Scand. J. Haematol. 5: 432-439.

50. Li, E. H. H., C. Orton, and R. D. Feinman. 1974. The interaction of thrombin and heparin: proflavin dye binding studies. Biochemistry. 13: 5012-5017.

51. Marciniak, E. 1974. Binding of heparin in vitro and in vivo to plasma proteins. J. Lab. Clin. Med. 84: 344-356.

52. Scott, J. E. 1973. Affinity, competition and specific interactions in the biochemistry and histochemistry of polyelectrolytes. Biochem. Soc. Trans. 1: 787-806.

53. Laurent, T. C. 1977. Interaction between proteins and glycosaminoglycans. Fed. Proc. 36: 24-27.

54. Burstein, M., and R. Morphin. 1969. Action de l'héparine et la protamine sur la mobilité électrophorétique des lipoprotéines sériques. Nouv. Rev. Fr. Hematol. 9: 365-374.

55. Burstein, M., and H. R. Scholnick. 1973. Lipoproteinpolyanion-metal interactions. Adv. Lipid Res. 11: 67108.

56. Machovich, R., G. Blasko, and L. Palos. 1975. Action of heparin on thrombin-antithrombin reaction. Biochim. Biophys. Acta. 379: 193-200.

57. Li, E. H. H., J. W. Fenton, and R. D. Feinman. 1976. The role of heparin in the thrombin-antithrombin III reaction. Arch. Biochem. Biophys. 175: 153-159.

58. Rosenberg, R. D., and P. S. Damus. 1973. The purification and mechanism of action of human antithrombinheparin cofactor. J. Biol. Chem. 248: 6490-6505.

59. Lipinska, I., B. Lipinski, and V. Gurewich. 1974. Fibrinogen heterogeneity in human plasma: electrophoretic demonstration and characterization of two major electrophoretic components. J. Lab. Clin. Med. 84: 509-516.

60. Nossel, H. L., I. Yudelman, R. W. Canfield, V. P. Butler, Jr., K. Spanondis, G. D. Wilner, and G. D. Qureshi. 1974. Measurement of fibrinopeptide A in human blood. J. Clin. Invest. 54: 43-53.

61. Mosesson, M. W., and J. S. Finlayson. 1974. The fibrinogenolytic pathway of fibrinogen catabolism: a rebuttal. Thromb. Res. 4: 895-900.

62. Finlayson, J. S., M. W. Mosesson, T. J. Bronzert, and J. J. Pisano. 1972. Human fibrinogen heterogeneities. II. Cross-linking capacity of high solubility catabolic intermediates: J. Biol. Chem. 247: 5220-5222.

63. Finlayson, J. S., and M. W. Mosesson. 1973. Crosslinking of $\alpha$ chain remnants in human fibrin. Thromb. Res. 2: 467-478.

64. Folk, J. E., and J. S. Finlayson. 1977. The $\epsilon$-( $\gamma$-glutamyl)lysine cross-link and the catalytic role of transglutaminases. Adv. Protein Chem. 31: 1-133. 